\title{
Multivariate statistical study of heavy metal enrichment in sediments of the Pearl River Estuary
}

\author{
W.X. Liua, ${ }^{\mathrm{a}, \mathrm{b}}$, X.D. Li ${ }^{\mathrm{a}, *}$, Z.G. Shen ${ }^{\mathrm{a}, \mathrm{c}}$, D.C. Wang ${ }^{\mathrm{a}}$, O.W.H. Wai ${ }^{\mathrm{a}}$, Y.S. Li ${ }^{\mathrm{a}}$ \\ ${ }^{a}$ Department of Civil and Structural Engineering, The Hong Kong Polytechnic University, Hung Hom, Kowloon, Hong Kong \\ ${ }^{\mathrm{b}}$ SKLEAC, Research Center for Eco-Environmental Sciences, Chinese Academy of Sciences, PO Box 2871, Beijing 100085, China \\ ${ }^{\mathrm{c}}$ Department of Agronomy, Nanjing Agricultural University, Nanjing 210095, China
}

Received 21 December 2001; accepted 11 May 2002

"Capsule": Multivariate statistical analysis identified the heavy metal accumulation layers of sediment profiles and showed the various sources of metals in the estuary.

\begin{abstract}
The concentrations and chemical partitioning of heavy metals in the sediment cores of the Pearl River Estuary were studied. Based on Pearson correlation coefficients and principal component analysis results, Al was selected as the concentration normalizer for $\mathrm{Pb}$, while $\mathrm{Fe}$ was used as the normalizing element for $\mathrm{Co}, \mathrm{Cu}, \mathrm{Ni}$ and $\mathrm{Zn}$. In each profile, sections with metal concentrations exceeding the upper $95 \%$ prediction interval of the linear regression model were regarded as metal enrichment layers. The heavy metal accumulation mainly occurred at sites in the western shallow water areas and east channel, which reflected the hydraulic conditions and influence from riparian anthropogenic activities. Heavy metals in the enrichment sections were evaluated by a sequential extraction method for possible chemical forms in sediments. Since the residual, Fe/Mn oxides and organic/sulfide fractions were dominant geochemical phases in the enriched sections, the bioavailability of heavy metals in sediments was generally low. The ${ }^{206} \mathrm{~Pb} /{ }^{207} \mathrm{~Pb}$ ratios in the metal-enriched sediment sections also revealed the influence of anthropogenic sources. The spatial distribution of cumulative heavy metals in the sediments suggested that the $\mathrm{Zn}$ and $\mathrm{Cu}$ mainly originated from point sources, while the $\mathrm{Pb}$ probably came from non-point sources in the estuary. (C) 2002 Elsevier Science Ltd. All rights reserved.
\end{abstract}

Keywords: Estuarine sediments; Heavy metals; Normalization; Enrichment; The Pearl River Estuary

\section{Introduction}

Estuaries are complex and dynamic environments, which receive large amounts of anthropogenic contaminants from nearby urban areas and industrial sites. Among the various contaminants, heavy metals are of particular concern due to their environmental persistence and biogeochemical recycling and ecological risks. The high total concentrations of heavy metals in sediments may not necessarily indicate anthropogenic contamination, because of different background levels in parent materials and sediment properties. The natural occurrence and chemical speciation of metals can also complicate the evaluation of potentially polluted aquatic sediments (Schiff and Weisberg, 1999).

* Corresponding author. Tel.: + 852-2766-6041; fax: + 852-23346389.

E-mail address: cexdli@polyu.edu.hk (X.D. Li).
Numerous efforts have been made to normalize the dilution effect invoked by coarse particles on metal contaminant concentrations in sediments, in order to understand the potential factors influencing the distribution of metals among different locations in a specific study area. The corresponding methods can be classified as the physical separation of different fractions in sediments and the mathematical normalization of the chemical data by a suitable sediment property (i.e. a reference element or constituent). The latter, containing ratio calculation and regression analysis, may be preferable, due to the difficulties associated with the efficiency and feasibility of mechanical separation presented in many cases. The reference element, a fundamental or conservative tracer of the natural metalbound phases, is assumed to have a uniform flux from the coastal bedrock. Therefore, the anthropogenic inputs of trace metals can be identified by alterations of the relationships between trace metals and the reference 
element (Luoma, 1990). However, there is no uniform protocol on the appropriate sediment constituent for metal concentration normalization. The common normalizers for heavy metal concentrations mainly include $\mathrm{Al}, \mathrm{Fe}$, total organic carbon (TOC) and Li. However, the accuracy or reliability of either $\mathrm{Al}$ or Fe may be not suitable if the contaminant source introduces large quantities of these two elements (Tam and Yao, 1998). TOC, without a geochemical basis, is also subject to considerable influence by human activities, and is often a pollutant by itself. Relationships between $\mathrm{Li}$ and trace metals in fine-grain sediments are usually similar to those of Al (Daskalakis and O'Connor, 1995).

The estuary sediments are usually derived from different mineralogical sources (e.g. of fluvial origin, marine provenance and mixtures). It is often impossible to find a single representative reference site for spatial comparison to detect and quantify anthropogenic pollution. Alternatively, the background variability of metal concentrations in sediments can be estimated or corrected by a baseline model of linear regression (Daskalakis and O'Connor, 1995; Chapman and Wang, 2001). This method fully considers the background concentrations of naturally occurring substances and provides important insight into the origins of contamination.

It is generally regarded that the bioavailability of heavy metals is closely related to their chemical forms, rather than the total concentration in sediments (Förstner, 1993). Heavy metals in sediments occur in different geochemical forms, which have distinct mobility, biological toxicity and chemical behaviors. It is essential to distinguish and quantify the various forms of metals to yield a better understanding of the potential and actual environmental impacts of contaminated sediments. However, direct determination of specific chemical forms is generally impractical due to various binding phases of metals and their structural properties. Alternatively, sequential extraction procedures, which define the metal activity by the analytical schemes, become preferred (Gonzalez et al., 2000). In addition, the isotopic composition of $\mathrm{Pb}$ has been utilized as an indication of pollution sources (Monna et al., 1999; Weiss et al., 1999), since the stable $\mathrm{Pb}$ isotope ratios in sediments usually depend on the parent materials and anthropogenic sources.

The Pearl River is the largest river system in Southern China, with an average water flow of $11,070 \mathrm{~m}^{3} / \mathrm{s}$. With fast economic growth and an increasing population in the area, the annual discharges of industrial wastewater and sewage water have risen to as much as 200 million and 40 million tons respectively (Wong et al., 1995). Consequently, the inputs of pollutants, particularly heavy metals, to the local aquatic environment are greatly increased. The objectives of the present study are: (1) to evaluate heavy metal enrichment in sediment profiles using the appropriate reference element ascertained by statistical correlation and principal component analysis, and (2) to examine the accumulation and bioavailability of heavy metals in sediments by the baseline model of linear regression, chemical partitioning, and $\mathrm{Pb}$ isotope composition analysis.

\section{Materials and methods}

\subsection{Sampling and sample preparation}

Sediment cores were collected in the estuary area (see Fig. 1) using a gravity corer equipped with an automatic clutch and reverse catcher. Each core was then sliced into sections at $10-\mathrm{cm}$ intervals from 0 to $1 \mathrm{~m}$ and at 20 $\mathrm{cm}$ intervals from 1 to $2 \mathrm{~m}$ in depth ( $\mathrm{Li}$ et al., 2000a). The physicochemical properties including organic matter (loss on ignition at $450{ }^{\circ} \mathrm{C}$ for $6 \mathrm{~h}$ ) and particle size distribution were determined according to the methods described by Mudrich et al. (1996).

\subsection{Chemical analysis}

Sediment samples $(0.1 \mathrm{~g})$, dried at $105^{\circ} \mathrm{C}$ and ground to pass through a $74-\mu \mathrm{m}$ sieve, were digested with a mixture of concentrated $\mathrm{HNO}_{3}(2 \mathrm{ml}), \mathrm{HClO}_{4}(1 \mathrm{ml})$ and $\mathrm{HF}(5 \mathrm{ml})$ at $90-190^{\circ} \mathrm{C}$ for $16 \mathrm{~h}$ in a heating block (Foss Tecator 2040 Digester). Afterwards, trace and major elements were determined by inductively coupled plasma-atomic emission spectrometry (ICP-AES, Perkin-Elmer Optima 3300DV). The details of the total metal concentration measurements can be found elsewhere (Li et al., 2000a).

Five operationally defined fractions can be obtained by sequential extraction procedures (Tessier et al., 1979; $\mathrm{Li}$ et al., 1995): the exchangeable form (1.0 $\mathrm{M} \mathrm{MgCl}_{2}$, $\mathrm{pH} 7.0$, for $20 \mathrm{~min})$, the carbonate bound form $(1.0 \mathrm{M}$ $\mathrm{NaOAc}, \mathrm{pH} 5.0$, for $6 \mathrm{~h}$ ), the $\mathrm{Fe} / \mathrm{Mn}$ oxide bound form (reducible phase; $0.04 \mathrm{M} \mathrm{NH}_{2} \mathrm{OHHCl}$ in $25 \% \mathrm{HOAc}$ at $96 \mathrm{C}$ for $6 \mathrm{~h}$ ), the organic matter/sulfides bound form (oxidized phase; $30 \% \mathrm{H}_{2} \mathrm{O}_{2}$ at $85 \mathrm{C}$ for $3 \mathrm{~h}$ ) and the residual form (total digestion with a concentrated mixture of $\mathrm{HNO}_{3}$ and $\mathrm{HClO}_{4}$ ). After each step, the separation of solid and solution was implemented by centrifuging at $2000 \mathrm{rpm}$ for $15 \mathrm{~min}$. The supernatant was then removed by pipette, and the residual sediment was rinsed by de-ionized water and centrifuged again. The washing water was discarded. Metal concentrations in solutions were acidified with $\mathrm{HNO}_{3}$ and measured using ICP-AES (ICP-AES, Perkin-Elmer Optima 3300DV; Li et al., 2000b, 2001).

For $\mathrm{Pb}$ stable isotope analysis, $1 \mathrm{ml}$ concentrated $\mathrm{HNO}_{3}$ and $4 \mathrm{ml}$ concentrated $\mathrm{HClO}_{4}$ were applied to each sample $(0.1 \mathrm{~g})$ in a boron silicate tube. All the tubes were heated at $150{ }^{\circ} \mathrm{C}$ for $1 \mathrm{~h}$, then at $180{ }^{\circ} \mathrm{C}$ for $5 \mathrm{~h}$ 


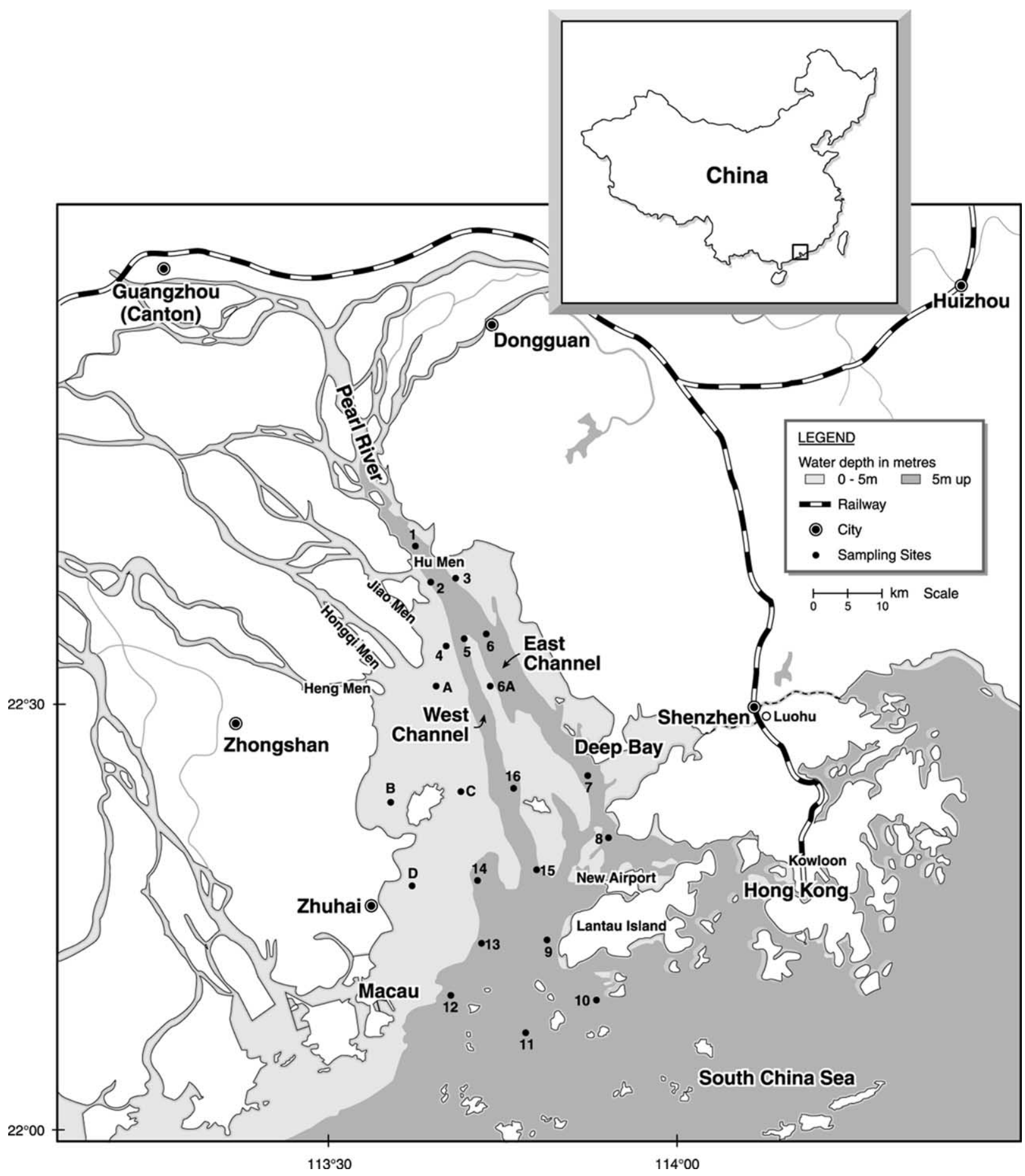

Fig. 1. A sketch map of sampling sites in the Pearl River Estuary.

(Munksgaard et al., 1998). After cooling, $2.5 \mathrm{ml}$ concentrated nitric acid was added into each tube and cooked at $120{ }^{\circ} \mathrm{C}$ for $30 \mathrm{~min}$. DIW $(20 \mathrm{ml})$ was then added, and the tubes were heated at $100{ }^{\circ} \mathrm{C}$ for $30 \mathrm{~min}$. At room temperature, the digesting solution was filtered through a Whatman 40 membrane into a $50-\mathrm{ml}$ volumetric flask and diluted to the total volume.

The $\mathrm{Pb}$ stable isotopes ${ }^{206} \mathrm{~Pb}$ and ${ }^{207} \mathrm{~Pb}$ were analyzed by inductively coupled plasma-mass spectrometry
(ICP-MS, Perkin-Elmer ELAN 6000), and calibrated by a standard reference material (RSM 981, NIST). The measured ${ }^{206} \mathrm{~Pb} /{ }^{207} \mathrm{~Pb}$ ratio for $\mathrm{RSM} 981$ was $1.0925 \pm 0.0019(n=8)$, compared to the reference value of 1.0933 . The average deviation of ${ }^{206} \mathrm{~Pb} /{ }^{207} \mathrm{~Pb}$ for duplicates was $0.24 \pm 0.34 \%(n=18)$.

In this study, standard reference materials were used to verify the accuracy of metal analysis in total concentration and the sequential extraction procedure. 
The recovery rates of heavy metals in the standard reference material were around $85-110 \%$. In addition, the cumulative concentrations of metals in sequential extraction sediments were comparable to the independent total concentrations, with recovery rates of 82 $104 \%$. Reagent blanks were also employed for background correction and random error calculation. At least one duplicate was run for every six samples to confirm the precision of the sequential extraction method. The precision and bias were less than $10 \%$ in all analyses.

\subsection{Statistical analysis}

All statistical calculations, including Pearson correlation coefficients, principal component analysis (PCA) and linear regression, were conducted using Statistica for Windows Ver. 4.5 (StatSoft Inc., USA).

\section{Results and discussion}

\subsection{Metal concentrations in the profiles}

The average and range of metal concentrations in the sediment cores, as well as some regional background values and sediment quality guidelines, are listed in Table 1. In comparison, the concentrations of $\mathrm{Cu}, \mathrm{Ni}$, $\mathrm{Pb}$ and $\mathrm{Zn}$ were generally elevated in the sediment cores. In addition, the average concentrations of these metals had increased in the last 20 years relative to the previous monitoring results (Wong et al., 1995). These results showed the influences of the increasing discharges of contaminants from local industrial, agricultural and urban activities.

The average metal concentrations in the surface or subsurface sections were generally higher than in the deeper layers, although the differences were small, and there were distinguish patterns among the individual profiles. The vertical distribution of metal concentrations is commonly affected by many factors, such as sediment properties, hydrodynamic conditions (surface waves, turbulence and tidal currents) and dredging activities. On the whole, three distribution patterns can be categorized for the individual cores in this study. The first is the mixed-up pattern at the top and bottom sections located in the river mouth area (close to the river channels), possibly due to annual dredging operations, effluent input and natural hydrodynamic conditions. The second is the enriched trend at the top layers of the profiles in the western coastal zones, which indicates the accumulation of metal pollutants from adjacent land sources under relatively stable and normal sedimentation processes, particularly in recent years. The last is the uniform pattern in the inter-tidal area, where strong mixing is caused by tidal currents, and the high salinity of the marine water facilitates the element diffusion through the profiles ( $\mathrm{Li}$ et al., 2000a).

\subsection{Selection of normalizer elements}

In most sedimentary environments, there is a linear relationship between inert element (normalizer) concentrations and the fine particle-size fractions (silt + clay) of the samples, which allows the use of normalizer concentrations as a substitute for the granulometric variability of the sediments. Therefore, geochemical normalization by a normalizer can compensate for both granulometric and mineralogical variability of metal concentrations in sediments (Aloupi and Angelidis, 2001). Reference elements as the metal concentration normalizer can be determined by statistical analyses. The Pearson correlation coefficients of trace and major elements and sediment properties in the cores are summarized in Table 2. The related results of PCA applied to the entire data set are listed in Table 3.

From Table 2, there were strong associations between $\mathrm{Co}, \mathrm{Cu}, \mathrm{Ni}$, and $\mathrm{Fe}$, whereas $\mathrm{Pb}$ displays a different behavior from these metals. Principal component analysis (PCA), a multivariate statistical technique, is generally employed to reduce the dimensionality of a data set while attempting to preserve the relationships present in the original data. In this study, three principal components (PC) can be extracted; they account for about $84 \%$ of the total variance. Based on the loading distribution of the metal variables in PCA (see Table 3), $\mathrm{Co}, \mathrm{Cu}, \mathrm{Ni}, \mathrm{Zn}$ and $\mathrm{Fe}$ constitute a firmly related group (PC 1), while another group is composed of $\mathrm{Pb}$ and $\mathrm{Al}$ (PC 2). These results are in agreement with the Pearson correlation coefficient matrix, which may indicate the different origins or controlling factors of the heavy metals in sediments, e.g. the lithogenous component (Rubio et al., 2000). As for $\mathrm{Mg}$ and $\mathrm{Ca}$ (PC 3), both are usually affiliated to the marine water and sedimentation processes ( $\mathrm{Li}$ et al., 2000a), and show apparent distinct patterns from other elements in the PCA.

Considering the significance of the correlation coefficient and principal component loading, Fe was better for $\mathrm{Co}, \mathrm{Cu}, \mathrm{Ni}$ and $\mathrm{Zn}$ normalization in these sediments than $\mathrm{Al}$, organic matter and fine fractions of grain-size ( $>63 \mu \mathrm{m}$, silt + clay), whereas aluminum was the most appropriate normalizer for $\mathrm{Pb}$ in the study area.

\subsection{Metal enrichment by the linear baseline model}

The naturally occurring metals should have a relatively uniform distribution with depth in all cores, since their concentrations in the sediments are not affected by the discharges from anthropogenic sources. To identify and evaluate the intensity of anthropogenic metals in the cores, natural variability has to be considered by normalizing data to a reference element. The relationships 
Table 1

Heavy metal concentrations and particle size distribution in different sediment sections of the profile

\begin{tabular}{|c|c|c|c|c|c|c|c|}
\hline Depth (cm) & Content & $\mathrm{Co}(\mathrm{mg} / \mathrm{kg})$ & $\mathrm{Cu}(\mathrm{mg} / \mathrm{kg})$ & $\mathrm{Ni}(\mathrm{mg} / \mathrm{kg})$ & $\mathrm{Pb}(\mathrm{mg} / \mathrm{kg})$ & $\mathrm{Zn}(\mathrm{mg} / \mathrm{kg})$ & $\mathrm{FP}^{\mathrm{a}}(\%)$ \\
\hline \multirow[t]{2}{*}{$0-5$} & Mean & 16.3 & 40.9 & 33 & 59.5 & 114.5 & 79.5 \\
\hline & Range & $5.8-18.8$ & $7.1-63$ & $7.5-48.5$ & $27-72$ & $32.3-210$ & $14.6-99.2$ \\
\hline \multirow[t]{2}{*}{$10-15$} & Mean & 13.6 & 40.4 & 32.6 & 57 & 111 & 79.7 \\
\hline & Range & $5.5-18$ & $6.4-60.9$ & $7.5-45$ & $19.5-82.5$ & $28.2-204$ & $11.2-99.1$ \\
\hline \multirow[t]{2}{*}{$20-25$} & Mean & 13.4 & 37.8 & 31.2 & 51.6 & 103.4 & 77 \\
\hline & Range & $4.8-19$ & $5.4-63.7$ & $7-46$ & $19.5-81$ & $26.6-187$ & $0.9-99.7$ \\
\hline \multirow[t]{2}{*}{$30-35$} & Mean & 13.3 & 37.5 & 31.4 & 52.3 & 113.4 & 74.2 \\
\hline & Range & $6-19$ & $6.6-67.6$ & $9.5-47$ & $22.5-91.5$ & $35.9-332$ & $17-99.8$ \\
\hline \multirow[t]{2}{*}{$40-45$} & Mean & 13.8 & 38.8 & 34.6 & 50.3 & 110.4 & 79.9 \\
\hline & Range & $6.8-20.3$ & $6.8-68.3$ & $10.5-91$ & $27-79.5$ & $41-229$ & $17.1-99.9$ \\
\hline \multirow[t]{2}{*}{$50-55$} & Mean & 13.8 & 39.1 & 32.3 & 50.4 & 102.2 & 78.4 \\
\hline & Range & $8.3-20.5$ & $7.9-74.3$ & $11.5-47.5$ & $30-76.5$ & $41-167$ & $16.5-99.7$ \\
\hline \multirow[t]{2}{*}{$60-65$} & Mean & 13.4 & 37.2 & 31.7 & 50.9 & 115.1 & 81.9 \\
\hline & Range & $8.5-20.3$ & $8.9-68.3$ & $11.5-49$ & $31.5-99$ & $47.8-239$ & $22.3-99.6$ \\
\hline \multirow[t]{2}{*}{$70-75$} & Mean & 13.4 & 37.5 & 32.1 & 48.4 & 101.2 & 80.2 \\
\hline & Range & $7.8-19.5$ & $8.5-66.7$ & $12-48.5$ & $30-88.5$ & $45.3-175$ & $25.6-99.7$ \\
\hline \multirow[t]{2}{*}{$80-85$} & Mean & 13.5 & 38 & 32.5 & 49.2 & 101.9 & 82.9 \\
\hline & Range & $7.5-19$ & $8.4-66.8$ & $11-46.5$ & $30-88.5$ & $40.5-183$ & $23.1-99.9$ \\
\hline \multirow[t]{2}{*}{ 90-95 } & Mean & 13.4 & 36.1 & 31.6 & 50.7 & 98.4 & 81.1 \\
\hline & Range & $6.8-20.3$ & $7.4-64.1$ & $10.5-49.5$ & $28.5-75$ & $37.7-154$ & $27.5-99.8$ \\
\hline \multirow[t]{2}{*}{$100-105$} & Mean & 13.7 & 37.2 & 32.8 & 49.6 & 99.9 & 85.5 \\
\hline & Range & $8-20.3$ & $9.2-65.1$ & $13-47.5$ & $30-90$ & $48.3-144$ & $26.1-99.9$ \\
\hline \multirow[t]{2}{*}{$120-125$} & Mean & 13.5 & 36.9 & 32.6 & 48.2 & 98.9 & 85.9 \\
\hline & Range & $7.5-19.3$ & $8.8-62$ & $12-46.5$ & $28.5-82.5$ & $42.9-126$ & $18.4-99.6$ \\
\hline \multirow[t]{2}{*}{$140-145$} & Mean & 13.6 & 38.7 & 33 & 49.2 & 100.9 & 86.5 \\
\hline & Range & $8.5-19.5$ & $9.4-66.1$ & $12-50.5$ & $33-90$ & $46.7-172$ & $25.9-99.6$ \\
\hline \multirow[t]{2}{*}{$160-165$} & Mean & 13.2 & 36 & 31.7 & 47 & 94.8 & 83.1 \\
\hline & Range & $7.3-19.8$ & $10.9-67.9$ & $13.5-50$ & $28.5-78$ & $44-125$ & $31.0-99.8$ \\
\hline \multirow[t]{2}{*}{$180-185$} & Mean & 12.9 & 33.9 & 31.4 & 49.7 & 95.4 & 84.5 \\
\hline & Range & $8.5-19.3$ & $9.8-61.5$ & $13.0-47$ & $30-87$ & $45.5-122$ & $30.6-99.3$ \\
\hline Coast $\mathrm{BK}^{\mathrm{b}}$ & Average & & 30 & & 25 & 80 & \\
\hline Marine $\mathrm{BK}^{\mathrm{c}}$ & Average & & 15 & 25 & 50 & 94 & \\
\hline Estuary $\mathrm{BK}^{\mathrm{d}}$ & Average & & 10 & 15 & 29 & 70 & \\
\hline $\mathrm{HK} \mathrm{BK}^{\mathrm{e}}$ & & & 7 & 10 & 19 & 40 & \\
\hline Target ${ }^{\mathrm{f}}$ & & & 20 & 20 & 35 & 75 & \\
\hline Trigger & & & 55 & 35 & 65 & 150 & \\
\hline Action $^{\mathrm{h}}$ & & & 65 & 40 & 75 & 200 & \\
\hline ISQV $^{\mathrm{i}}$-Low & & & 65 & 40 & 75 & 200 & \\
\hline ISQV $^{\mathrm{i}}$ - High & & & 270 & $\mathrm{ND}^{\mathrm{j}}$ & 218 & 410 & \\
\hline
\end{tabular}

a Fine fractions of particles $(<63 \mu \mathrm{m}$, silt + clay $)$.

b Background values of Chinese coastal areas (Zheng et al., 1992).

c Background values of the marine sediments in Hong Kong (Tanner et al., 2000).

d Background values of the estuary sediments in Hong Kong (Tanner et al., 2000).

e Local background levels in Hong Kong (Lau et al., 1993).

${ }^{\mathrm{f}}$ Desired quality for fairly clean sediment, slightly exceeding but close to the background levels (Lau et al., 1993).

g Moderate pollution, equated to about $50 \%$ of the trigger levels (Lau et al., 1993).

h Heavy pollution (Lau et al., 1993).

${ }^{i}$ Interim sediment quality values (ISQVs, Chapman et al., 1999).

${ }^{j}$ No data.

between trace metals and reference elements in the baseline data set can show the range of naturally occurring concentrations of trace metals. The upper $95 \%$ prediction interval, derived from the linear regression model, can form a baseline range to segregate anthropogenic inputs from natural variations of metal concentrations in the bulk sediments (Sokal and Rohlf, 1995; Doherty et al., 2000). In this study, the upper $95 \%$ prediction interval was utilized for identifying metal enrichment in the sediment sections. The linear regression results, as well as the upper $95 \%$ prediction intervals and the low levels of the ISQVs, are illustrated in Fig. 2.

All data-points which fall inside the $95 \%$ confidence band can be designated as natural sediments with no pollution disturbance, while points above this area can 
Table 2

Pearson correlation matrix for the metal concentrations and sediment properties ${ }^{\mathrm{a}}$

\begin{tabular}{|c|c|c|c|c|c|c|c|c|c|}
\hline Element & $\mathrm{Fe}$ & $\mathrm{Al}$ & $\mathrm{OM}^{1}$ & $\mathrm{FP}^{2}$ & $\mathrm{Co}$ & $\mathrm{Cu}$ & $\mathrm{Ni}$ & $\mathrm{Pb}$ & $\mathrm{Zn}$ \\
\hline $\mathrm{Fe}$ & 1.000 & 0.770 & 0.766 & 0.795 & 0.885 & 0.900 & 0.905 & 0.426 & 0.714 \\
\hline $\mathrm{Al}$ & & 1.000 & 0.770 & 0.778 & 0.558 & 0.637 & 0.680 & 0.641 & 0.632 \\
\hline $\mathrm{OM}^{\mathrm{b}}$ & & & 1.000 & 0.837 & 0.582 & 0.677 & 0.715 & 0.495 & 0.622 \\
\hline $\mathrm{FP}^{\mathrm{c}}$ & & & & 1.000 & 0.629 & 0.719 & 0.773 & 0.433 & 0.602 \\
\hline $\mathrm{Co}$ & & & & & 1.000 & 0.954 & 0.924 & 0.213 & 0.685 \\
\hline $\mathrm{Cu}$ & & & & & & 1.000 & 0.945 & 0.271 & 0.753 \\
\hline $\mathrm{Ni}$ & & & & & & & 1.000 & 0.276 & 0.701 \\
\hline $\mathrm{Pb}$ & & & & & & & & 1.000 & 0.553 \\
\hline $\mathrm{Zn}$ & & & & & & & & & 1.000 \\
\hline
\end{tabular}

a All correlation is significant at $P<0.05(N=267)$.

b Organic matter (loss on ignition).

${ }^{c}$ Fine fractions of particles $(<63 \mu \mathrm{m}$, silt + clay $)$.

Table 3

Principal component (PC) loading of heavy metals and sediment properties $^{\mathrm{a}}$

\begin{tabular}{|c|c|c|c|}
\hline Variable & $\begin{array}{l}\text { PC } 1 \\
(62.96 \%)\end{array}$ & $\begin{array}{l}\text { PC } 2 \\
(11.61 \%)\end{array}$ & $\begin{array}{l}\text { PC } 3 \\
(9.40 \%)\end{array}$ \\
\hline $\mathrm{Mg}$ & 0.29 & 0.16 & 0.92 \\
\hline $\mathrm{Ca}$ & -0.44 & -0.52 & 0.56 \\
\hline $\mathrm{Mn}$ & 0.78 & 0.20 & -0.03 \\
\hline $\mathrm{Fe}$ & 0.80 & 0.43 & 0.36 \\
\hline $\mathrm{Al}$ & 0.44 & 0.81 & 0.12 \\
\hline $\mathrm{OM}^{\mathrm{b}}$ & 0.49 & 0.70 & 0.27 \\
\hline $\mathrm{FP}^{\mathrm{c}}$ & 0.56 & 0.66 & 0.27 \\
\hline Co & 0.95 & 0.15 & 0.12 \\
\hline $\mathrm{Cu}$ & 0.95 & 0.26 & 0.07 \\
\hline $\mathrm{Ni}$ & 0.89 & 0.32 & 0.17 \\
\hline $\mathrm{Pb}$ & 0.06 & 0.85 & 0.06 \\
\hline $\mathrm{Zn}$ & 0.67 & 0.49 & 0.00 \\
\hline
\end{tabular}

be considered as sediments with heavy metals accumulated from anthropogenic sources. In the regression plot between the total metal concentrations and the appropriate normalizers, the data points below the upper $95 \%$ prediction limit probably originated from natural sources. From Fig. 2, the strength of the linear relationships, in terms of correlation coefficient $\left(r^{2}\right)$, partially confirms the applicability of $\mathrm{Fe}$ for $\mathrm{Co}, \mathrm{Cu}, \mathrm{Ni}$ and $\mathrm{Zn}$, and $\mathrm{Al}$ for $\mathrm{Pb}$ as the concentration normalizers in this study. Based on the corresponding number of sediment sections ( $n_{1}$ and $n_{2}$ in Fig. 2), heavy metals with total concentrations beyond the two threshold ranges mainly involve $\mathrm{Pb}, \mathrm{Zn}$ and $\mathrm{Cu}$. This result reflects, to a large extent, the constituent characteristics of metal contaminant sources in the river system, including industrial discharges and domestic sewage from riparian areas, as well as marine traffic and runoff from upstream mining activities (Chen and Zhou, 1992).

For the spatial distribution, most metal-enriched sediment sections were located in the western coastal zone (e.g. Cores A, B, C and D) and the east channel of the estuary (such as Cores 6,7 and 8). The patterns reflect that the hydraulic conditions (e.g. slow current) and high clay contents may facilitate the pollutant deposition in the western shallow water areas. The inputs from the main tributaries and marine traffic, and strong mixing effects can cause elevated heavy metal concentrations in the east channels (Li et al., 2000a).

\subsection{Metal chemical forms in the enrichment sections}

In general, the results of the background enrichment approach, based on a linear regression model, do not necessarily imply biological effects of the contaminants in sediments. However, metal enrichment identification can be utilized as a sifting tool to assist cost-effective use of sediment toxicity tests. Therefore, only those with metal concentrations exceeding the expected natural background levels will be further studied on toxicity (Chapman and Wang, 2001). Since mobility, biological availability and potential toxicity of heavy metals are generally dependent on their existing chemical forms (Förstner, 1993), it is important to identify the chemical species of heavy metals in the sediments of interest. Accordingly, the chemical partitioning of heavy metals in the enriched sections, identified by the linear regression model, is presented in Table 4. Because most enriched sections occurred in the range of $0-65 \mathrm{~cm}$ depth based on the linear baseline model, for simplicity, enriched sections deeper than $65 \mathrm{~cm}$ are not included.

From Table 4, the dominant binding phases for $\mathrm{Cu}, \mathrm{Pb}$ and $\mathrm{Zn}$ were the residual, $\mathrm{Fe} / \mathrm{Mn}$ oxides and organic matters/sulfide fractions, which are generally regarded as relatively stable or inert under normal conditions. Among the non-residual fractions, $\mathrm{Pb}$ was mainly associated 

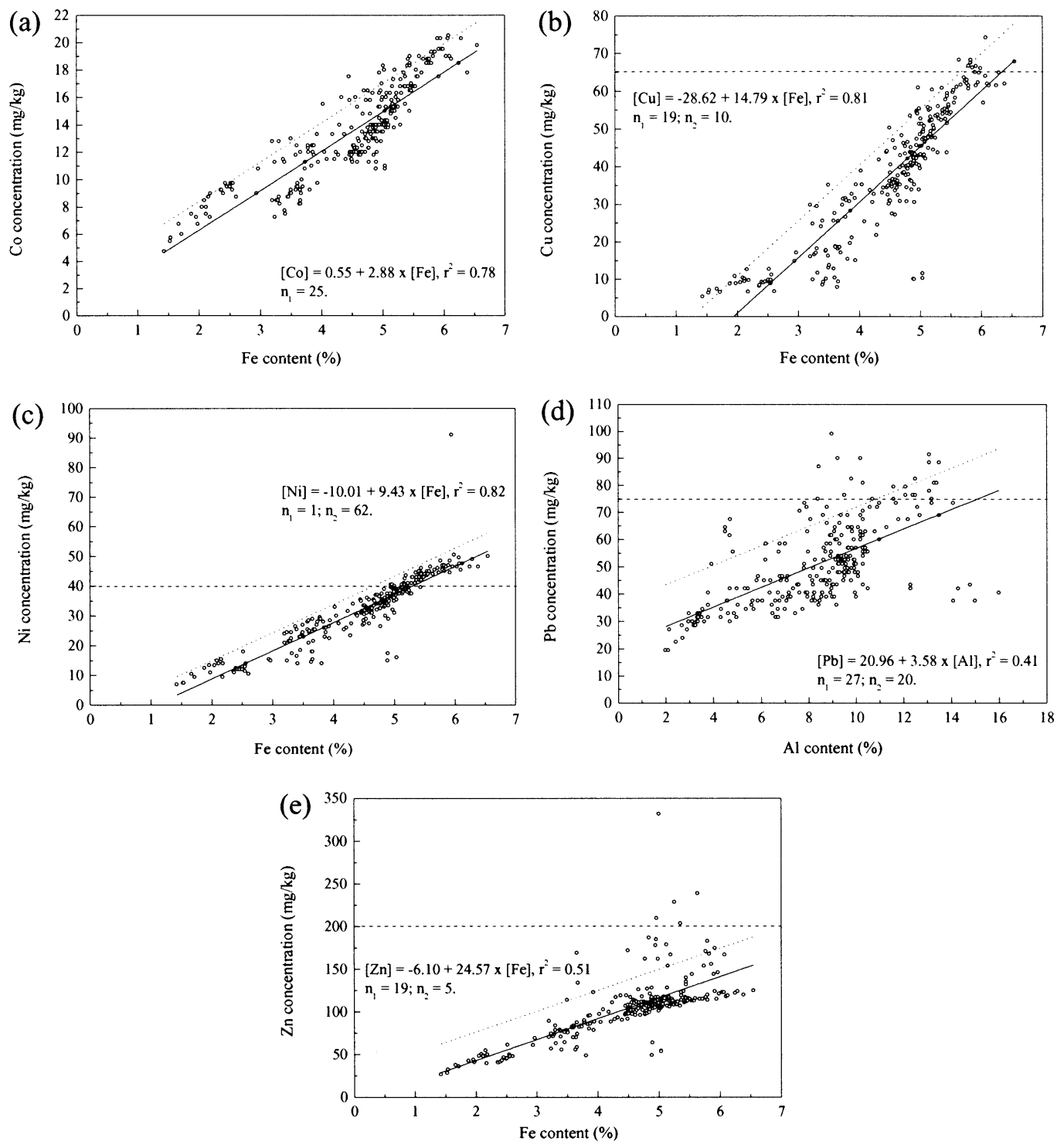

Fig. 2. Scatter plots of the linear regression models $(N=267)$ : (a) $\mathrm{Co}$; (b) $\mathrm{Cu}$; (c) $\mathrm{Ni}$; (d) $\mathrm{Pb}$ and (e) $\mathrm{Zn}$. The solid line is the linear regression equation. The dotted and dashed lines indicate the upper $95 \%$ prediction interval based on the linear regression model and the low ISQV value of each metal, respectively. The incorporated equations represent the linear regression relationships. The $n_{1}$ and $n_{2}$ denote the number of sections with metal concentration above the upper $95 \%$ prediction interval and above the low ISQVs, respectively.

with the $\mathrm{Fe} / \mathrm{Mn}$ oxide fraction. Besides the $\mathrm{Fe} / \mathrm{Mn}$ oxide fraction, the organic/sulfide fraction was another dominant binding phase of $\mathrm{Zn}$. For $\mathrm{Cu}$, the organic/sulfide fraction was an important carrier. The contributions of active species, such as exchangeable and carbonate/specifically adsorped fractions, are generally low in the sediments. However, the proportions of $\mathrm{Pb}$ in the carbonate/specifically adsorbed fraction were relatively high in some cores (see Table 4), which may indicate recent input from anthropogenic sources.

\subsection{Pb isotope compositions of the sediments}

Analysis of $\mathrm{Pb}$ stable isotopes in the sediment column can help to identify various sources of $\mathrm{Pb}$ in an estuary environment (Farmer et al., 1996; Munksgaard et al., 1998; $\mathrm{Li}$ et al., 2001). In general, the ${ }^{206} \mathrm{~Pb} /{ }^{207} \mathrm{~Pb}$ ratio can be used for assessing anthropogenic inputs of $\mathrm{Pb}$ in soils and sediments. In many cases, the geochemical background $\mathrm{Pb}$ generally has a high ${ }^{206} \mathrm{~Pb} /{ }^{207} \mathrm{~Pb}$ ratio, while the $\mathrm{Pb}$ from recent industrial discharges or other anthropogenic inputs displays a relatively low ratio. The natural background of ${ }^{206} \mathrm{~Pb} /{ }^{207} \mathrm{~Pb}$ ratios is $1.197-1.198$ (mean value) in the Pearl River Estuary; a decrease in the ratio may suggest the occurrence of anthropogenic sources (Zhu et al., 2001). From the ${ }^{206} \mathrm{~Pb} /{ }^{207} \mathrm{~Pb}$ ratio in aerosols $(1.151 \pm 0.010)$ and in the fly ash of coal combustion $(1.169 \pm 0.021)$ collected in Hong Kong, the atmospheric input of $\mathrm{Pb}$ in the estuary is estimated to have an isotope ratio of 1.15-1.17 (Wong et al., 2002). 
Table 4

Percentage of different chemical forms to total metal concentrations in the metal-enriched sections

\begin{tabular}{|c|c|c|c|c|c|c|}
\hline Metal (Core No.) & Depth $(\mathrm{cm})$ & Exchangeable & Carbonate & $\mathrm{Fe} / \mathrm{Mn}$ oxide & Organic/sulfide & Residue \\
\hline \multirow[t]{2}{*}{$\mathrm{Pb}($ Core 2) } & $0-5$ & 1.3 & 8.9 & 20.3 & 9.8 & 59.7 \\
\hline & $10-15$ & 1.3 & 4.5 & 27.1 & 9.3 & 57.8 \\
\hline \multirow[t]{2}{*}{$\mathrm{Cu}$ (Core 4) } & $0-5$ & 0.0 & 15.3 & 25.8 & 7.3 & 51.6 \\
\hline & $10-15$ & 0.0 & 15.4 & 22.8 & 8.0 & 53.8 \\
\hline $\mathrm{Zn}($ Core 5$)$ & $60-65$ & 0.0 & 0.2 & 19.4 & 29.8 & 50.6 \\
\hline \multirow[t]{5}{*}{$\mathrm{Pb}$ (Core 6) } & $0-5$ & 1.5 & 7.3 & 25.3 & 12.7 & 53.3 \\
\hline & $10-15$ & 1.1 & 6.0 & 21.0 & 14.4 & 57.4 \\
\hline & $20-25$ & 1.3 & 7.4 & 29.4 & 11.8 & 50.0 \\
\hline & $30-35$ & 0.9 & 6.3 & 20.2 & 11.7 & 60.9 \\
\hline & $50-55$ & 1.5 & 8.4 & 20.8 & 14.0 & 55.4 \\
\hline \multirow[t]{3}{*}{ Zn (Core 6) } & $10-15$ & 0.0 & 5.6 & 27.8 & 13.2 & 53.5 \\
\hline & $30-35$ & 0.4 & 4.5 & 18.1 & 50.2 & 26.8 \\
\hline & $40-45$ & 0.0 & 5.0 & 19.5 & 39.2 & 36.3 \\
\hline \multirow[t]{5}{*}{$\mathrm{Pb}($ Core 7$)$} & $0-5$ & 0.7 & 19.7 & 30.6 & 12.5 & 36.4 \\
\hline & $10-15$ & 0.5 & 17.3 & 32.1 & 15.8 & 34.2 \\
\hline & $20-25$ & 0.3 & 16.1 & 33.4 & 14.3 & 35.9 \\
\hline & $30-35$ & 0.5 & 18.8 & 29.4 & 16.0 & 35.3 \\
\hline & $40-45$ & 0.5 & 18.3 & 24.3 & 18.7 & 38.2 \\
\hline Zn (Core 7) & $60-65$ & 0.0 & 0.7 & 22.2 & 29.2 & 47.9 \\
\hline Zn (Core 8) & $60-65$ & 0.0 & 0.0 & 32.8 & 32.2 & 35.0 \\
\hline \multirow[t]{6}{*}{$\mathrm{Cu}($ Core A) } & $10-15$ & 0.7 & 6.8 & 10.5 & 18.2 & 63.8 \\
\hline & $20-25$ & 0.6 & 7.8 & 10.5 & 18.4 & 62.7 \\
\hline & $30-35$ & 0.5 & 8.0 & 8.2 & 15.6 & 67.7 \\
\hline & $40-45$ & 0.4 & 7.8 & 9.8 & 15.7 & 66.2 \\
\hline & $50-55$ & 0.4 & 8.6 & 9.2 & 15.3 & 66.5 \\
\hline & $60-65$ & 0.5 & 7.5 & 10.9 & 18.4 & 62.7 \\
\hline \multirow[t]{3}{*}{$\mathrm{Pb}$ (Core A) } & $0-5$ & 0.0 & 13.9 & 34.4 & 21.1 & 30.6 \\
\hline & $10-15$ & 0.0 & 17.3 & 35.0 & 19.7 & 28.0 \\
\hline & $60-65$ & 0.0 & 14.7 & 33.0 & 21.3 & 31.0 \\
\hline \multirow[t]{4}{*}{ Zn (Core A) } & $0-5$ & 0.0 & 0.7 & 42.8 & 7.6 & 48.9 \\
\hline & $10-15$ & 0.0 & 0.9 & 41.3 & 8.4 & 49.4 \\
\hline & $20-25$ & 0.0 & 3.4 & 44.1 & 8.6 & 43.9 \\
\hline & $60-65$ & 0.0 & 3.6 & 42.1 & 9.7 & 44.5 \\
\hline \multirow[t]{5}{*}{$\mathrm{Cu}$ (Core B) } & $0-5$ & 0.6 & 2.3 & 13.1 & 16.5 & 67.5 \\
\hline & $10-15$ & 0.2 & 1.6 & 9.7 & 14.4 & 74.1 \\
\hline & $20-25$ & 0.2 & 2.1 & 8.5 & 14.3 & 74.9 \\
\hline & $40-45$ & 0.2 & 1.2 & 11.7 & 16.2 & 70.7 \\
\hline & $60-65$ & 0.2 & 0.6 & 7.0 & 12.6 & 79.7 \\
\hline \multirow[t]{3}{*}{$\mathrm{Pb}$ (Core B) } & $0-5$ & 0.1 & 2.3 & 49.2 & 27.0 & 21.5 \\
\hline & $10-15$ & 0.1 & 5.1 & 49.0 & 25.2 & 20.5 \\
\hline & $20-25$ & 0.1 & 4.9 & 49.2 & 26.3 & 19.5 \\
\hline \multirow[t]{5}{*}{ Zn (Core B) } & $0-5$ & 0.1 & 3.7 & 34.8 & 12.6 & 48.9 \\
\hline & $10-15$ & 0.1 & 3.7 & 30.2 & 11.3 & 54.8 \\
\hline & $20-25$ & 0.1 & 3.6 & 31.3 & 13.7 & 51.3 \\
\hline & $30-35$ & 0.1 & 3.9 & 33.0 & 12.1 & 50.9 \\
\hline & $40-45$ & 0.1 & 4.5 & 29.0 & 13.4 & 53.1 \\
\hline \multirow[t]{2}{*}{$\mathrm{Cu}($ Core $\mathrm{C})$} & $0-5$ & 0.2 & 1.4 & 12.8 & 19.5 & 66.2 \\
\hline & $10-15$ & 0.1 & 1.4 & 11.9 & 20.0 & 66.6 \\
\hline Zn (Core C) & $0-5$ & 0.0 & 3.1 & 36.4 & 6.9 & 53.6 \\
\hline Zn (Core D) & $0-5$ & 0.1 & 6.5 & 34.1 & 11.6 & 47.7 \\
\hline
\end{tabular}


The excessive range of ${ }^{206} \mathrm{~Pb} /{ }^{207} \mathrm{~Pb}$ ratio in the top sediments was close to that of fly ash, therefore coal burning by industries, such as power plants, and the subsequent atmospheric deposition may be one of the major sources of $\mathrm{Pb}$ in the sediments ( $\mathrm{Li}$ et al., 2000a).

In the sections with $\mathrm{Pb}$ enrichment assessed by the linear regression model, the ${ }^{206} \mathrm{~Pb} /{ }^{207} \mathrm{~Pb}$ ratios are either the lowest or among the lowest values in the sediment profiles (see Table 5). The ratio values derived from the upper sediment sections are generally lower than those of the deeper sections, indicating that the enrichment of heavy metals in sediments mainly results from local industrial operations and urbanization during recent decades.

\subsection{Quantitative evaluation of metal enrichment}

The Pearl River delta is the most rapidly developing region in China. Large amounts of untreated wastewater and sewage, especially from metal industries, have caused degeneration in the environmental quality of the Pearl River Estuary. To evaluate trace metal contamination, the regression calculation can be combined with PCA and other multivariate methods (Shine et al., 1995; Doherty et al., 2000). After normalization using $\mathrm{Fe}$ or $\mathrm{Al}$, the correlation coefficients and the PCA analyses, performed on the metal/normalizer ratios in the entire profiles and at the top layers, are shown in Tables 6 and 7, respectively.

Based on the normalized concentrations, the correlation coefficients of $\mathrm{Cu}, \mathrm{Pb}$ and $\mathrm{Zn}$ with $\mathrm{Co}$ decreased significantly compared with the total concentration results (see Table 2), and the correlation coefficients of $\mathrm{Cu}$ and $\mathrm{Zn}$ with $\mathrm{Pb}$ were changed from positive values to negative values. On the other hand, the strong association between $\mathrm{Cu}$ and $\mathrm{Ni}$ persists to a large extent after normalization (see Table 2). In the PCA results, the first two principal axes retained 73.2 and $89.2 \%$ of the total variance for the data on the entire cores and the top layers, respectively. Further, two main clusters of metal variables could be classified with the normalized metal concentrations: one consisting of $\mathrm{Co}, \mathrm{Cu}, \mathrm{Ni}$ and $\mathrm{Zn}$, and the other consisting of only $\mathrm{Pb}$. Like the case of the Pearson correlation coefficients, notable variations were observed for $\mathrm{Co}$ and $\mathrm{Pb}$ on the principal component axes when using normalized concentrations of heavy metals (see Fig. 3). The change in the loading of $\mathrm{Cu}, \mathrm{Ni}$ and perhaps $\mathrm{Zn}$ is, however, relatively small. Therefore, the normalization of metal concentrations with $\mathrm{Fe}$ or $\mathrm{Al}$ can further identify and clarify the relationships between different heavy metals, and their actual geochemical characteristics, such as $\mathrm{Co}$ and $\mathrm{Pb}$ in this study.

Table 6

Pearson correlation coefficients of the normalized metal concentrations in the sediment cores (upper panel, $N=267$ ) and in the top layers (lower panel, $N=18)^{\mathrm{a}}$

\begin{tabular}{llllrr}
\hline Metal & $\mathrm{Co}$ & $\mathrm{Cu}$ & $\mathrm{Ni}$ & $\mathrm{Pb}$ & \multicolumn{1}{c}{$\mathrm{Zn}$} \\
\hline $\mathrm{Co}$ & 1.000 & $\mathbf{0 . 1 9 0}$ & $\mathbf{0 . 2 5 0}$ & $\mathbf{0 . 1 8 4}$ & 0.087 \\
$\mathrm{Cu}$ & & 1.000 & $\mathbf{0 . 8 1 4}$ & $\mathbf{- 0 . 5 6 8}$ & $\mathbf{0 . 3 3 7}$ \\
$\mathrm{Ni}$ & & & 1.000 & $-\mathbf{0 . 6 2 8}$ & $\mathbf{0 . 2 8 8}$ \\
$\mathrm{Pb}$ & & & & 1.000 & -0.030 \\
$\mathrm{Zn}$ & & & & & 1.000 \\
& & & & & \\
$\mathrm{Co}$ & 1.000 & 0.316 & 0.261 & 0.114 & $\mathbf{0 . 5 5 8}$ \\
$\mathrm{Cu}$ & & 1.000 & $\mathbf{0 . 9 4 3}$ & $-\mathbf{0 . 6 3 5}$ & $\mathbf{0 . 7 0 8}$ \\
$\mathrm{Ni}$ & & & 1.000 & $-\mathbf{0 . 8 1 7}$ & $\mathbf{0 . 5 8 5}$ \\
$\mathrm{Pb}$ & & & & 1.000 & -0.125 \\
$\mathrm{Zn}$ & & & & & 1.000 \\
\hline
\end{tabular}

a The bold values denote significance level at $P<0.05$.

Table 5

Distribution of ${ }^{206} \mathrm{~Pb} /{ }^{207} \mathrm{~Pb}$ ratio in the selected sediment cores $^{\mathrm{a}}$

\begin{tabular}{lllllllll}
\hline Depth $(\mathrm{cm})$ & Core 2 & Core 5 & Core 6 & Core 7 & Core 9 & Core 14 & Core A & Core B \\
\hline $0-5$ & $\mathbf{1 . 1 9 1}$ & 1.198 & $\mathbf{1 . 1 9 1}$ & $\mathbf{1 . 1 8 8}$ & 1.192 & 1.186 & $\mathbf{1 . 1 8 4}$ \\
$10-15$ & $\mathbf{1 . 1 9 2}$ & 1.198 & $\mathbf{1 . 1 8 0}$ & $\mathbf{1 . 1 9 2}$ & 1.197 & 1.198 & $\mathbf{1 . 1 8 1}$ \\
$20-25$ & 1.201 & 1.198 & 1.191 & $\mathbf{1 . 1 8 9}$ & 1.182 & 1.197 & 1.184 \\
$30-35$ & 1.187 & 1.197 & $\mathbf{1 . 1 8 6}$ & $\mathbf{1 . 1 9 1}$ & 1.196 & 1.193 & 1.191 \\
$40-45$ & 1.197 & 1.197 & 1.183 & $\mathbf{1 . 1 9 2}$ & 1.196 & 1.201 & 1.188 \\
$50-55$ & 1.198 & 1.201 & $\mathbf{1 . 1 8 8}$ & 1.191 & 1.196 & 1.199 & 1.190 \\
$60-65$ & 1.194 & 1.192 & 1.169 & 1.199 & 1.194 & 1.200 & 1.194 \\
$70-75$ & & & & & & 1.179 \\
$80-85$ & 1.201 & $\mathbf{1 . 1 8 7}$ & 1.189 & 1.197 & 1.194 & 1.198 & 1.180 \\
$90-95$ & 1.201 & $\mathbf{1 . 1 8 7}$ & 1.196 & 1.194 & 1.198 & 1.198 & 1.186 \\
$100-105$ & 1.193 & 1.190 & 1.201 & 1.192 & 1.190 & 1.190 & 1.180 \\
$120-125$ & $\mathbf{1 . 1 8 9}$ & 1.194 & 1.188 & 1.196 & 1.198 & 1.203 & 1.189 \\
$140-145$ & 1.198 & 1.186 & 1.183 & 1.198 & 1.194 & 1.195 & 1.199 \\
$160-165$ & $\mathbf{1 . 1 9 5}$ & 1.193 & 1.196 & 1.199 & $\mathbf{1 . 1 8 9}$ & 1.195 & 1.199 \\
$180-185$ & $\mathbf{1 . 1 9 4}$ & 1.189 & $\mathbf{1 . 1 8 6}$ & 1.197 & 1.188 & 1.198 & 1.198 \\
\end{tabular}

a The bold values denote the sections with anthropogenically enriched $\mathrm{Pb}$ based on metal concentrations normalized by $\mathrm{Al}$ in the linear regression model. 


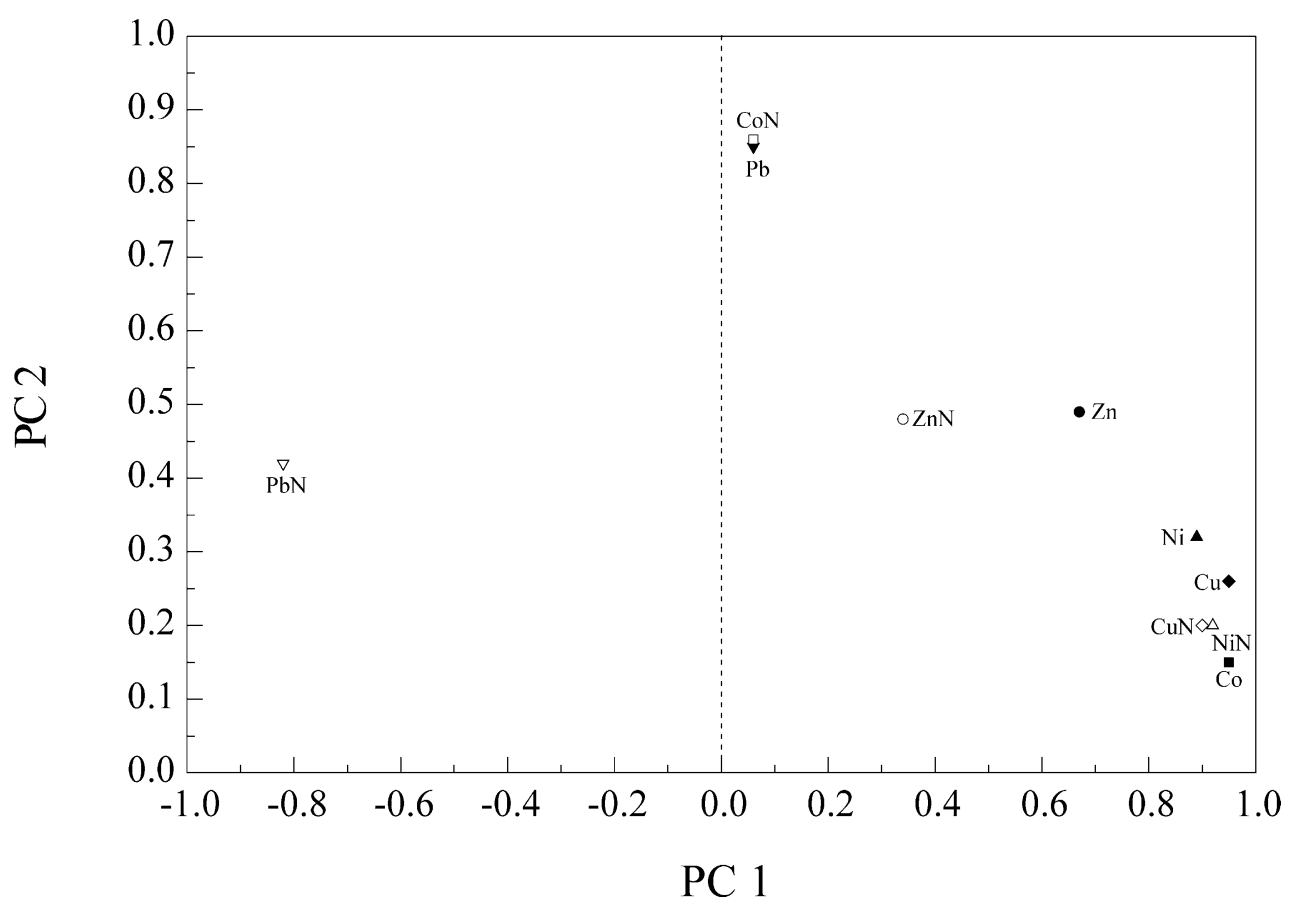

Fig. 3. Comparison of the principal component loading of metal variables between the original concentrations and the normalized concentrations in the sediment cores. $\mathrm{CoN}, \mathrm{CuN}, \mathrm{NiN}, \mathrm{PbN}$ and $\mathrm{ZnN}$ represent normalized concentrations of $\mathrm{Co}, \mathrm{Cu}, \mathrm{Ni}, \mathrm{Pb}$ and $\mathrm{Zn}$ respectively.

Table 7

Principal component loading of PCA based on the normalized metal concentrations in the cores (upper panel, $N=267$ ) and in the top layers (lower panel, $N=18$ )

\begin{tabular}{lll}
\hline Variable & PC $1(49.55 \%)$ & PC 2 $(23.68 \%)$ \\
\hline $\mathrm{Co}$ & 0.06 & 0.86 \\
$\mathrm{Cu}$ & 0.90 & 0.20 \\
$\mathrm{Ni}$ & 0.91 & 0.20 \\
$\mathrm{~Pb}$ & -0.82 & 0.42 \\
$\mathrm{Zn}$ & 0.34 & 0.48 \\
& & \\
& $\mathrm{PC} 1(61.89 \%)$ & PC 2(27.32\%) \\
$\mathrm{Co}$ & -0.03 & 0.89 \\
$\mathrm{Cu}$ & 0.85 & 0.45 \\
$\mathrm{Ni}$ & 0.95 & 0.30 \\
$\mathrm{~Pb}$ & -0.93 & 0.21 \\
$\mathrm{Zn}$ & 0.38 & 0.83
\end{tabular}

The percentage in parentheses is the contribution of the principal component to the total variance.

The element associations obtained by correlation coefficient and principal component score can indicate different origins of heavy metals in the sediments. The feature of point sources lies in that the inputs of heavy metals occur over a finite period of time and may have been effectively retained in the sediments near the sources, rather than re-suspended and distributed uniformly throughout the region. Distinct from point sources, metals from non-point sources are more uniformly distributed throughout the area (Shine et al., 1995).
Combined with the previous results (Li et al., 2000a), the sources of heavy metals in the sediments of the Pearl River Estuary differ for each element, but may include: (1) polluted tributaries as well as the weathering release of parent materials in the local bedrock, such as $\mathrm{Cu}$ and $\mathrm{Ni}$; (2) terrestrial discharge of wastewater from the upstream area, accounting for the $\mathrm{Zn}$; and (3) atmospheric transport and precipitation, exemplified by $\mathrm{Pb}$ (i.e. airborne $\mathrm{Pb}$ ).

In view of the environmental significance of surficial sediments due to mass exchange with the overlying water and direct exposure to aquatic organisms (e.g. plankton and benthos), the principal component scores of the top layers $(0-5 \mathrm{~cm})$ and relevant loading of metal variables are depicted in Fig. 4. Four large groups of surface sediment samples can be approximately categorized according to a score plot showing the positions of samples in the coordinates of the principal component. They are (1) Cores A, B, C, D and 2, (2) Cores 7 and 8 , (3) Cores 4 and 6 , and (4) other sampling cores (see Fig. 4). In Fig. 4, it is clear that the spatial (or geographical) distributions of metal enrichment at shallower depths (above $65 \mathrm{~cm}$ ) in the sediment cores are mainly in the western shallow water zone and in the east channel. The patterns confirm the results obtained from the linear regression models (see Table 4).

Furthermore, considering the principal component loading of metal variables (see Table 7 and Fig. 4), enrichment of $\mathrm{Cu}, \mathrm{Ni}$ and $\mathrm{Zn}$ with both positive loading along the two principal component axes is evident in the 


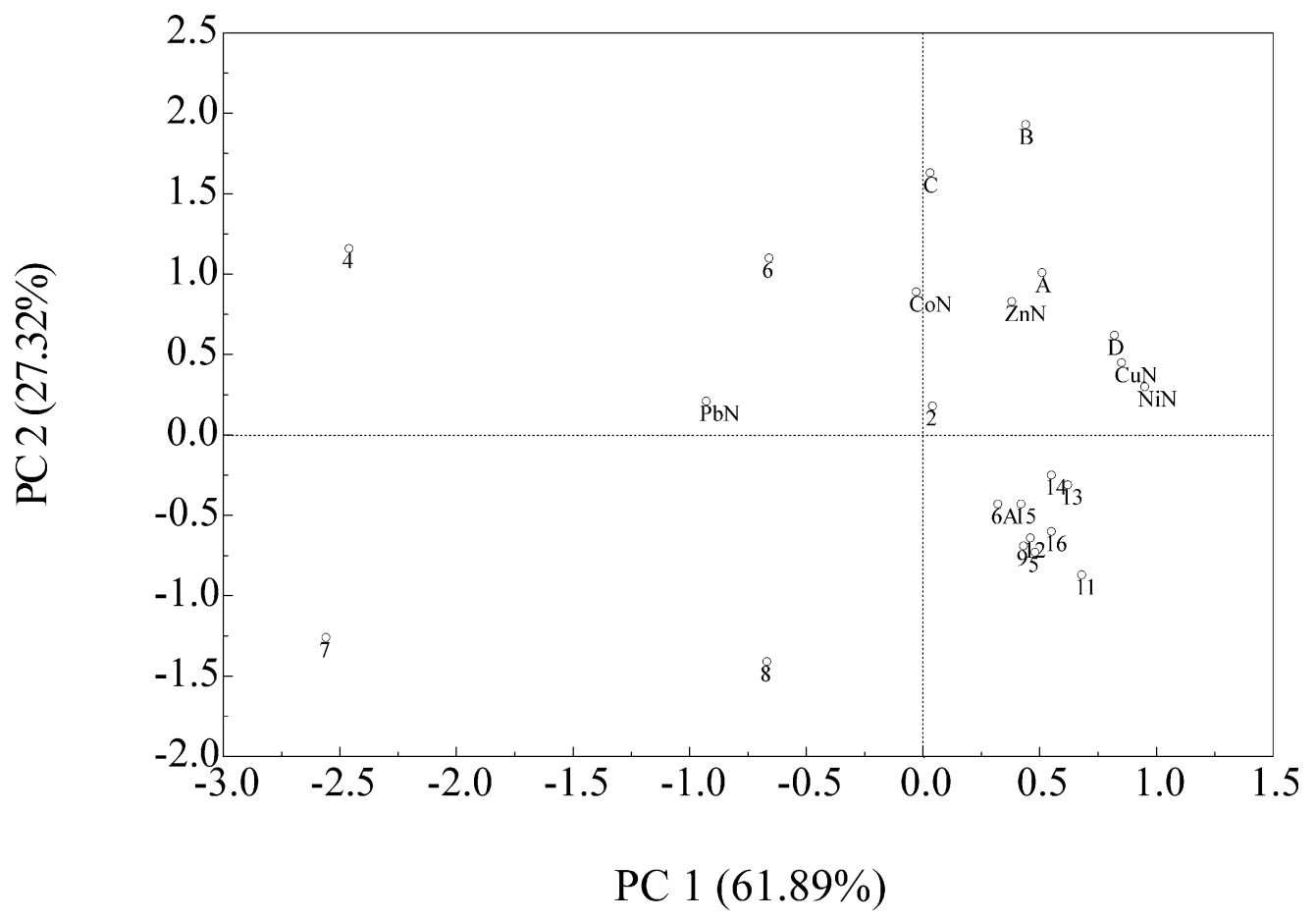

Fig. 4. Principal component scores of the surface sediment samples $(0-5 \mathrm{~cm})$ and principal component loading of metal variables using the normalized metal concentrations by $\mathrm{Fe}$ or $\mathrm{Al} . \mathrm{CoN}, \mathrm{CuN}, \mathrm{NiN}, \mathrm{PbN}$ and $\mathrm{ZnN}$ represent normalized concentrations of $\mathrm{Co}, \mathrm{Cu}, \mathrm{Ni}, \mathrm{Pb}$ and $\mathrm{Zn}$ respectively.

western shallow water area of the estuary. This can be attributed to both the direct discharges from point sources, such as rivers and creeks carrying metal contaminants, and the relatively constant sedimentation conditions. On the other hand, $\mathrm{Pb}$ probably arises from non-point sources, for instance, atmospheric deposition. These features can be reinforced by other related studies (Li et al., 2000a, 2001).

\section{Conclusions}

The concentrations of $\mathrm{Cu}, \mathrm{Pb}$ and $\mathrm{Zn}$ in the surface sediments of the Pearl River Estuary were elevated, especially in the western shallow region, reflecting the anthropogenic inputs from industrial development and urbanization in the last few decades. The normalization of heavy metal concentrations to suitable reference elements ( $\mathrm{Fe}$ for $\mathrm{Cu}$ and $\mathrm{Zn}$, and $\mathrm{Al}$ for $\mathrm{Pb}$ ) could help to identify metal accumulation in sediment profiles. The residual, $\mathrm{Fe} / \mathrm{Mn}$ oxide and organic/sulfide fractions were the dominant geochemical phases for heavy metals in these metal-enriched sediment layers. The $\mathrm{Pb}$ stable isotope composition also showed the anthropogenic sources of heavy metals in the sediments. In addition, multivariate statistical analysis indicated that $\mathrm{Cu}$ was derived from the weathering of parent materials and polluted streams. Elevated Zn mainly originated from the discharges of point sources along the coast, particularly from the main tributaries in the northwestern estuary. $\mathrm{Pb}$ could have come from non-point sources, such as atmospheric deposition.

\section{Acknowledgements}

The project was funded by The Hong Kong Polytechnic University and the Research Grants Council of the Hong Kong SAR Government (PolyU 5075/99E). Assistance from Perkin-Elmer Hong Kong Ltd. on the $\mathrm{Pb}$ stable isotope analysis with ICP-MS is gratefully acknowledged.

\section{References}

Aloupi, M., Angelidis, M.O., 2001. Normalization to lithium for the assessment of metal contamination in coastal sediment cores from the Aegean Sea, Greece. Marine Environmental Research 52, 1-12.

Chapman, P.M., Allard, P.J., Vigers, G.A., 1999. Development of sediment quality values for Hong Kong Special Administrative Region: a possible model for other jurisdictions. Marine Pollution Bulletin 38, 161-169.

Chapman, P.M., Wang, F.Y., 2001. Assessing sediment contamination in estuaries. Environmental Toxicology and Chemistry 20, 3-22.

Chen, J.S., Zhou, J.Y., 1992. Heavy Metal Research in the Aquatic Environment of China. Environmental Science Press of China, Beijing, China.

Daskalakis, K.D., O'Connor, T.P., 1995. Normalization and elemental sediment contamination in the coastal states. Environmental Science and Technology 29, 470-477.

Doherty, G.B., Brunskill, G.J., Ridd, M.J., 2000. Natural and enhanced concentrations of trace metals in sediments of Cleveland 
Bay, Great Barrier Reef Lagoon, Australia. Marine Pollution Bulletin 41, 337-344.

Farmer, J.G., Eades, L.J., Mackenzie, A.B., Kirika, A., BaileyWatts, T.E., 1996. Stable lead isotope record of lead pollution in Loch Lomond sediments since 1630 A.D. Environmental Science and Technology 30, 3080-3083.

Förstner, U., 1993. Metal speciation-general concepts and applications. International Journal of Environmental Analytical Chemistry $51,5-23$.

Gonzalez, A.E., Rodriguez, M.T., Sanchez, J.C.J., de la Rosa, F.J.B., 2000. Assessment of metals in sediments in a tributary of Guadalquivir River (Spain): heavy metal partitioning and watersediments interaction. Water, Air and Soil Pollution 121, 11-29.

Lau, M.M., Rootham, R.C., Bradley, G.C., 1993. A strategy for the management of contaminated dredged sediment in Hong Kong. Journal of Environmental Management 38, 99-114.

Li, X.D., Coles, B.J., Ramsey, M.H., Thornton, I., 1995. Sequential extraction of soils for multielement analysis by ICP-AES. Chemical Geology 124, 109-123.

Li, X.D., Wai, O.W.H., Li, Y.S., Coles, B.J., Ramsey, M.H., Thornton, I., 2000a. Heavy metal distribution in sediment profiles of the Pearl River Estuary. Applied Geochemistry 15, 567-581.

Li, X.D., Shen, Z.G., Wai, O.W.H., Li, Y.S., 2000b. Chemical partitioning of heavy metal contaminants in sediments of the Pearl River Estuary. Chemical Speciation and Bioavailability 12, 17-25.

Li, X.D., Shen, Z.G., Wai, O.W.H., Li, Y.S., 2001. Chemical forms of $\mathrm{Pb}, \mathrm{Zn}$ and $\mathrm{Cu}$ in the sediment profiles of the Pearl River Estuary. Marine Pollution Bulletin 42, 215-223.

Luoma, S.N., 1990. Processes affecting metal concentrations in estuarine and coastal marine sediments. In: Furness, R., Rainbow, P. (Eds.), Heavy Metals in the Marine Environment. CRC Press, Boca Raton, Florida, USA, pp. 51-66.

Monna, F., Dominik, J., Loizeau, J., Pardos, M., Arpagaus, P., 1999. Origin and evaluation of $\mathrm{Pb}$ in sediments of Lake Geneva (Switzerland and France). Establishing a stable $\mathrm{Pb}$ record. Environmental Science and Technology 33, 2850-2857.

Mudrich, A., Azcue, J.M., Mudroch, P., 1996. Manual of Physicochemical Analysis of Aquatic Sediments. CRC Press Inc, Boca Raton, Florida, USA.

Munksgaard, N.C., Batterham, G.T., Parry, D.L., 1998. Lead isotope ratios determined by ICPMS: investigation of anthropogenic lead in seawater and sediment from the Gulf of Carpentaria, Australia. Marine Pollution Bulletin 36, 527-534.

Rubio, B., Nombela, M.A., Vilas, F., 2000. Geochemistry of major and trace elements in sediments of the Ria de Vigo (NW Spain): an assessment of metal contamination. Marine Pollution Bulletin 40, 968-980.

Schiff, K.C., Weisberg, S.B., 1999. Iron as a reference element for determining trace metal enrichment in Southern California coastal shelf sediments. Marine Environment Research 48, 161-176.

Shine, J.P., Ika, R.V., Ford, T.E., 1995. Multivariate statistical examination of spatial and temporal patterns of heavy metal contamination in New Bedford Harbor marine sediments. Environmental Science and Technology 29, 1781-1788.

Sokal, R., Rohlf, F., 1995. Biometry, third ed. Freeman, W. H. Press, New York, USA.

Tam, N.F.Y., Yao, M.W.Y., 1998. Normalization and heavy metal contamination in mangrove sediments. The Science of the Total Environment 216, 33-39.

Tanner, P.A., Leong, L.S., Pan, S.M., 2000. Contamination of heavy metals in marine sediment cores from Victoria Harbor, Hong Kong. Marine Pollution Bulletin 40, 769-779.

Tessier, A., Campbell, P.G.C., Bisson, M., 1979. Sequential extraction procedure for the speciation of trace metals. Analytical Chemistry 51,844851 .

Weiss, D., Shotyk, W., Applyby, P.G., Kramers, J.D., Cheburkin, A.K., 1999. Atmospheric Pb deposition since the industrial revolution recorded by five Swiss peat profiles: enrichment factors, fluxes, isotopic composition, and sources. Environmental Science and Technology 33, 1340-1352.

Wong, C.K., Chu, K.H., Chen, Q.C., Ma, X.L., 1995. Environmental Research in Pearl River and Coastal Areas. Guangdong Higher Education Press, Guangzhou, China.

Wong, S.C., Li, X.D., Zhang, G., Qi, S.H., Min, Y.H., 2002. Heavy metals in agricultural soils of the Pearl River Delta, South China. Environmental Pollution 119, 33-44.

Zheng, Q.H., Liang, Z.Q., He, Y.Q., Wen, W.Y., 1992. Geochemical behavior of the pollutants in surface sediments of Daya Bay. Tropical Oceanology (in Chinese) 11, 65-71.

Zhu, B.Q., Chen, Y.W., Peng, J.H., 2001. Lead isotope geochemistry of the urban environment in the Pearl River Delta. Applied Geochemistry 16, 409-417. 